\title{
Baruch Halpern
}

\section{From Gods to God}

\author{
The Dynamics of Iron Age Cosmologies \\ Ed. by Matthew J. Adams
}

[Von den Göttern zu Gott. Die Dynamik der Eisenzeitkosmologie.]

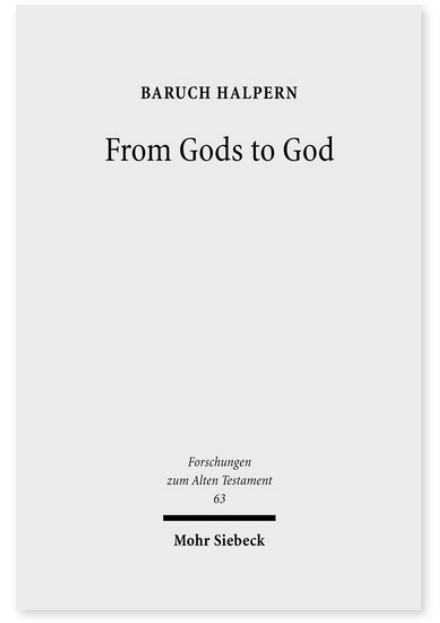

2009. XIV, 556 Seiten. FAT 63

ISBN 978-3-16-151104-2

DOI 10.1628/978-3-16-151104-2

eBook PDF $144,00 €$

ISBN 978-3-16-149902-9

Leinen $144,00 €$
Veröffentlicht auf Englisch.

Für die Entstehung des Westens war die Achsenzeit (800-400 v. Chr.) unentbehrlich. Baruch Halpern untersucht den Einfluß sich verändernder Kosmologien und sozialer Beziehungen auf den kulturellen Wandel dieser Epoche und insbesondere auf die Gebiete von Mesopotamien bis Israel und Griechenland, aber auch über den Mittelmeerraum hinaus bis Ägypten und Italien. Der Autor zeigt einen enormen Anstieg internationalen Handels und Austauschs: eine Renaissance, die zu einer Neudefinition des Selbst in verschiedenen Kulturen führte und damit zu einer Reformation beitrug. Dieser Prozeß beschleunigte unausweichlich eine Aufklärung. Er ist seit jeher Teil der Geschichte und findet periodisch in wissenschaftlichen oder kulturellen Bereichen statt. Er stellt die Basis für eine Modernisierung oder Verwestlichung dar, wo immer sie in irgendeiner Form stattfindet.

Baruch Halpern Born 1954; 1978 PhD; 1976-1992 Lecturer through Professor of Humanities, York University; since 1992 Professor at Pennsylvania State University; currently Chaiken Family Chair of Jewish Studies, Professor of Ancient History, Classics and Ancient Mediterranean Studies, and Religious Studies; (Life) Fellow, Institute of the Arts and Humanities at Pennsylvania State University; member of Graduate Faculty, Near, Middle Eastern and Jewish Studies, University of Toronto.

Matthew J. Adams Keine aktuellen Daten verfügbar.

Jetzt bestellen:

https://mohrsiebeck.com/buch/from-gods-to-god-9783161511042?no_cache=1

order@mohrsiebeck.com

Telefon: $+49(0) 7071-923-17$

Telefax: $+49(0) 7071-51104$ 